\title{
Consumer Perceptions Towards Package Designs: A Cross Cultural Study
}

\author{
Romica Chandra Lal \\ San Jose State University \\ romica.chandra27@gmail.com
}

\author{
Fritz Yambrach
}

San Jose State University

Fritz.Yambrach@sjsu.edu

\section{Lucy McProud}

San Jose State University

Lucy.McProud@sjsu.edu

\begin{abstract}
The choice of one package or the other can be an economic decision or can be influenced by cultural acceptance or perception of individual convenience. Product package systems can be designed for onetime use or multiple-use purposes. Package perceptions in different countries typically develop from a variety of factors, including climate, lifestyle, and cultural acceptance with regard to particular products. In an increasingly global economy with multinational firms marketing products worldwide, it is important to understand the differences between consumer needs and consumer responses to product-package systems. The objective of this research was to examine consumer perceptions of different product package systems by surveying residents from seven countries (Brazil, China, France, Germany, Italy, USA and Vietnam). Secondarily, this research examined cultural attitudes and values about packaging by surveying consumer perceptions of eight different package styles and materials as they relate to sustainability, secondary use, product expectations, quality, hygiene, and ease of use.

Trends and patterns among countries were identified using descriptive statistics. Results indicated a relationship between both individualistic and collectivistic orientation, as well as country status as developing or developed, with regard to consumer perceptions of product packaging. There also appeared to be a relationship between prevailing attitudes toward environmental sustainability and perceptions of product packaging. It is hoped that this research may be useful for companies exporting or seeking to export their products into other markets.
\end{abstract}

Key Words: Product package system, perception, package design, consumer behavior, Tetra Pak®, sustainable, secondary use, 'Pkg'(package), and package system 


\section{INTRODUCTION}

Traditionally the primary function of a package has been to protect the product from whatever might happen to it or whatever it might be exposed to during transit and handling. At the most basic level, packaging in the consumer product market household serves the dual purpose of storage and preservation. In addition to that, packaging now offers additional functionalities, including dispensing, sub-unit division, aesthetic appreciation, and secondary use. This applies to a wide range of products, including food, drugs, healthcare items, hardware, and more. The functionalities of package systems have been developing along with the technological sophistication that has grown to meet the demand for convenience. One prime example is the dispensing and dosing mechanisms that have been designed into health care products and beverage containers.

Product package systems can be designed for one-time use or multiple-use purposes. The choice of one or the other can be a function of perception of individual convenience or cultural acceptance. Package design has been determined to be one of the main factors in the consumer purchase decision [1]. In the retail environment, packaging represents one of the first points of contact between the product and consumer. The consumer develops an impression of the product based on the package's presentation, which may or may not lead to a sale [2]. Packaging can act as a voiceless salesperson that projects an image, purpose, and functionality of the product.

Because of the significant differences between cultures, it is natural to wonder whether and how a particular package design would be perceived differently in various cultural contexts. The increasing globalization of the world economy has created both increasing opportunities and challenges for companies to market their products internationally. With this in mind, it becomes increasingly important for companies to understand how to package their products for different markets to maximize the product offering.

This package design fit is especially important when launching new brands and introducing entirely new package designs or materials. A package system can be defined as a container with closure features that hold one or more components. Any nature of material can be used to create a package. The package can function as protection, containment, handling, delivery system and preservation of goods from the producer to the consumer [3]. Packaging also serves as an informational and marketing tool in retail. The package can function as a display on retail shelves and provide transparency features in its design to allow consumers to view the product's quality. Attractive graphic design on packaging labels can attract consumer's attention in shopping aisles [4]. Packaging labels also communicate information to the consumer, such as quantity, instructions for use, or ingredients. The package label can provide traceability identifiers for manufacturers, retail stores, and consumers.

The package may also provide a service function for the product. Re-sealable caps may be featured on package systems to offer food storage and portability features. Dosage control can be designed into pharmaceutical and commercial use packages to offer convenience to consumers [5]. Safety features in packaging, such as child resistant packaging helps prevent the occurrence of harmful accidental poisoning in children [6].

The amount of packaging in a society reflects the society's needs, cultural patterns, material availability, and technology [4]. In order for packaging to meet the needs of different constantly changing markets, packaging must continue to adapt 
as well. Packaging plays an important role at various stages of product transport and consumption. These roles can be grouped into four categories: Protection, Transportation, Mechanical Handling, and Informing/selling.

\section{PACKAGE FUNCTIONS}

\section{Protection:}

Packaging protects products by providing a barrier to maintain quality in foods, sterility of medical devices/pharmaceuticals; and a shield from various manual, mechanical, and microbiological hazards. Packaging can act as a barrier to protect food products from deterioration and contamination. The container can also provide a suitable environment for its product, so as to preserve color, smell or taste of a food product. The package system can provide a barrier to restrict movement of gases or water vapor coming in or out of the package, as gas exchange in certain food items can result in spoilage to certain foods or drugs, and the gain or loss of moisture can dramatically affect a product. Overall the package system helps extend the shelf life of many foods, as well as insuring the sterility of a food or medical device, and maintaining product quality by acting as a barrier to slow down or eliminate degenerative reactions.

\section{Transportation:}

A package system not only protects the quality of its product on retail shelves or in consumers' homes, it also helps protect the product from the stresses inherent in the distribution system, allowing the product to reach its destination undamaged. The package may encounter various atmospheric conditions, storage conditions or stresses during warehouse and vehicle stacking in delivery trucks. The stresses of shock from vibration produced during transport and handling, and compression during vehicle stacking, are just a few examples of the hazards that the package system may encounter during distribution [7]. Because of these stresses, technical packaging functions are designed into packaging, so as to facilitate safe distribution of the product [4].

\section{Mechanical Handling:}

Distribution packaging can be described as the movement of individual units combined into a unit load that can be moved around mechanically using a forklift or pallet jack through a warehouse and distribution systems [8]. A palletized unit load provides shipment of package systems consisting of many subsystems through the physical distribution environment, such as transporting, mechanical handling, and warehousing [4]. Forklifts can help mechanically move large loads on pallets from the manufacturer's site to a warehouse for storage, then onto a truck, for shipping to a retail shop [4]. Through all of these events the palletized load must be secure and strong enough to be lifted and moved by a lift truck, and this can be done using stretch film, which helps unitize the pallet load and provides protection to the packages against moisture, dirt and abrasion [9]. Not only does the package provide multiple levels of protection for the product, it also helps market the product inside to potential consumers.

\section{Informing/selling:}

Just as conserving and protecting the product's quality are important functions of a package system, so is the marketing role that packaging plays in informing and selling. The package communicates to the customer product information, and creates feelings and associations at a psychological level by branding and positioning the product in the mind of the consumer [10]. The communication can be direct 
with text describing product attributes or subtle by using colors. Package design and material choices can help express ideas and concepts of the product. Barber and Alamanza [11] reported that many consumers based their purchase on the information and description that was provided on the wine bottle's label rather than seeking guidance through journals or specialized shops. Indirect communication, such as visual aesthetics in a package's color, shape and size are a few attributes that catch a consumer's attention in a crowded retail aisle. The type of material the product is packaged in may increase or decrease the consumer's perception of the product's value and relative status on the ladder of its product category. A bottle of water packaged in a plastic container may be perceived as an economical choice, because plastic is commonly seen as an inexpensive material, as opposed to water packaged in a glass container which is perceived as higher quality. The physical characteristics of a package, such as color and shape, on store shelves can serve to attract consumer attention. Company and product information, relating to level of trust and credibility, can be communicated through package labels and brand identity, which may increase the chances of a sale. The more familiar consumers are with a product and package, the more comfortable and accepting they may be in making the purchase.

Packaging has multiple functions in product protection, distribution cycle and on retail shelves. Packaging protects its products from the hazards of the distribution cycle, while package design is used in marketing as a tool to sell products. People from different cultures are generally accustomed to certain packaging material for particular products, holding expectations of particular package designs due to their climate, geography and cultural norms. In Europe and developing countries consumers are accustomed to finding their dairy products packaged in Tetra Paks ${ }^{\circledR}$, an aseptic package system that provides ambient storage conditions for liquid products [12]. Products in Tetra Paks ${ }^{\circledR}$ can be transported in un-refrigerated trucks through various climatic conditions, and sit on storage shelves while maintaining the quality and hygiene of the product inside. In the United States consumers find their dairy products packaged in cartons or high-density polyethylene bottles that are stored under refrigeration. These package material types are stored and transported under refrigeration [13]. These differences in expectations based on economical and cultural differences may encourage or deter an individual from choosing particular product-packaging.

In today's highly global economy, it is vital to understand particular consumer needs and desires, in order to design package systems to be accepted by different cultures and countries. Differences in financial and cultural values must be considered as part of the process. This investigation was intended to shed light on perceptions that influence product purchase decisions in different cultural contexts, including the spectrum of individualistic versus collectivist cultures, following Geert Hofstede's five dimensions relating to cultural value differences [14].

\section{PURCHASING INFLUENCES}

There are many factors that influence purchasing decisions. Whether the package is the appropriate size for the consumer's needs may be a deciding factor. Consumer preference of color and aesthetics may influence the consumer's purchase choice. The cost of the product itself is important when making a purchase. The price of the product, brand, package size, color and package material are a few contributing influences with regard to purchasing decisions. 


\section{Price:}

As companies begin to expand into different sectors of the global market place, it is important to understand the differences in purchasing behaviors between consumers in developed and lesser developed economies. Consumers in developing countries have been shown to be highly influenced in their purchase decisions by family members than consumers in more developed countries. This may be because consumers in lesser developed countries tend to be more financially dependent on family members [15]. The relative cost of products is another factor in purchasing decisions made by this group. An inappropriate purchasing decision in the context of a lesser developed country can have significant financial repercussions for the purchaser and the purchaser's family. In contrast, consumers in more highly developed economies have greater freedom in experimentation, and trying out new products, without the risk of creating financial hardships for themselves or their family unit. This would help to explain greater product/brand/store loyalty on the part of consumers in lower socio-economic groups.

Consumers in less developed countries purchase smaller amounts of groceries more frequently throughout the week, due to low cash reserves and limited storage capacity [16]. Hypermarkets and supermarkets are rare in developing countries; this means that consumers must purchase foods from a variety of different vendors. For example, they will buy meat from a butcher, bread from a bakery, and fruit and vegetables from specialty stores [16]. Less robust and protective packaging may be required for these countries, since they are purchasing fresh items daily that may be consumed within a day instead of storage for later use. The lower the amount of packaging materials that are required for these purchases may help reduce the price of the product.

\section{Brand:}

The package system provides an identity and familiarity to a product's brand. Customers tend to become attached to certain brands because of their positive experiences with the brand's product, and it does not matter if the brands increase their price or change package features, since the customers will remain loyal to their brand [17]. Brands can act as a symbol or sign to describe a type of product. For example, if a customer asks a sales associate for a Kleenex type product, the sales associate will know that the customer is looking for facial tissue; the brand has established familiarity in the market place for this particular product. Consumers become loyal to certain brands because of the consistent positive experiences that they have received during product use, and this loyalty can increase the probability of repeat purchasing decisions and brand familiarity [18].

An international marketing survey conducted by The Nielson company found that $60 \%$ of individuals across North America, South America, Europe, Middle East and Asia would most likely purchase new products from brands they are familiar with [19]. The brand can be used as an instrument to expand its products in the market, once it has delivered trusted products and gained loyal customers.

\section{Package Size:}

Individuals in the developing world may purchase local goods or create ho me-grown goods, as this is more economical [20]. At the same time, many consumers from developing countries prefer foreign brands, because they reflect a higher status and signify social mobility [21]. Coca-Cola, an iconic global brand, has achieved a high level of market penetration in many countries around the world, including emerging markets such as India, Indonesia, 
and the Philippines [22]. Due to carbonated drinks being highly desirable items in these markets, and typically considered luxury items, and difficult for the average person to afford, but the ownership of luxury items conveys status, such as wearing popular and designer clothing brands, like Nike and Lululemon. In an effort to achieve greater market penetration, making greater inroads with consumers in lower socio-economic groups, Coca-Cola began offering single serving units in such countries as the Philippines at a lower cost, which is a strategy that has proven highly successful [22]. Coca-Cola launched this product in a small returnable 200 $\mathrm{ml}$ glass bottle, calling it sakto, meaning "exactly" (in Tagalog). The new bottle offered an attractive quantity at an attractive price. After this resulted in a widely circulated joke that sakto was a poor people's drink because it was something they could "exactly" afford, Coca-Cola then launched a new one-time use $300 \mathrm{ml}$ polyethylene (PET) bottle with a re-sealable capped closure system. The product was still affordable for the target teenage market, but considered more desirable because of its differences from the predecessor product (i.e., larger size, disposable, re-sealable, and no longer connected with the sakto name). With this adjustment, CocaCola succeeded in producing a product that was considered fun and hip.

This example illustrates an important theme in purchasing behavior in developing countries, where many consumers wish to purchase "just enough," small product-package systems, because of limited funds and storage facilities, in contrast with more developed countries where these considerations do not play as much of a major role in purchasing decisions.

\section{Color:}

Bonnardel, Beniwal, Dubey, Pande, and Bimler [23] examined color preferences in college students in India and the United Kingdom and reported that pastel colors (e.g., light blue and lavender) were regarded more favorably by British females than their Indian counterparts. Olive green was least favorably regarded by British males, in comparison with their Indian college counterparts, who regarded the color favorably. Overall, the study found that males in both groups preferred blue and green colors, whereas the females in both groups preferred pink and purple [23].

Colors may also hold symbolic meanings in various cultures. In an article on cultural color associations by Aslam [24], found that red is considered the color of ambition and desire in India, but has unlucky associations in Germany, Nigeria, and Chad; it is considered a masculine color in the UK and a bride's color in China [24]. In the UK, white is widely regarded as cheap and low-quality. In the US, darker colors are associated with high quality, elegance, and richness in an aesthetic sense.

These color associations inevitably affect consumer purchase decisions. Color association is therefore an important consideration in international marketing. Marketers can utilize colors to brand and position their products, with desired associations, translating into greater success at the cash register [25]. The Ty-D-Bol toilet bowl cleanser changed its package color from light blue and green to white letters on a dark background, projecting an image of "stronger and cleaner," as opposed to the original colors, which were deemed to have been too "wimpy," the switch in colors resulted in an increase in sales by an impressive 40\% [25]. Cultural beliefs and values are determinants that influence the popularity of an item, explaining why color and package size, together with price, affect consumer purchasing decisions. 


\section{Package Material:}

Packaging style and material plays a role in consumers' decision making; the package may convey product quality and status. Studies have shown that the packaging of wine has a great influence on purchasing choices [26]. The wine package style and appearance present a status and image that consumers may want to present to others [26]. Consumers' comprehension of product and package systems may be derived from the packaging material, a research study on food packaging conducted in South Africa found that glass was perceived to hold high quality products while folding boxed cartons looked cheap and did not portray a strong impression [27]. Venter, Merwe, Beer, Kempen, \& Bosman [27] study also evaluated plastic pouches and found that many respondents felt that the plastic pouches would be a one-time use package system that would be unable to protect food items once the pouch had been opened, potentially a good food package for picnics and road trips. The package material may influence the consumers purchase decision based on perceived status and quality of the package system.

\section{CULTURAL DIFFERENCES}

\section{Collectivist vs. Individualistic:}

Social psychologist Geert Hofstede has identified differences between collectivist and individualistic cultures [14]. Different purchasing choice and package needs may possibly be implied by this dichotomy. A collectivist culture is more focused on the needs of the group or the family, as opposed to the desires and goals of the individual. In comparison with a collectivist culture, an individualistic culture focuses more on the individual's needs, independence, and personal identity [28]. Individualistic cultures are more "me" centered. Members of individualistic societies look after themselves and immediate family members. Members of collectivist cultures expect the same loyalty in return from the members of their group. Collectivist cultures are more concerned with the common good of their group or extended family. Individuals in a collectivist society may be influenced by the norms of their group [29].

These cultural differences can be manifested in package design, in terms of materials used, as well as the size and type of package, and how the particular culture perceives the package with regard to convenience and environmental impact. Based on these cultural norms, it would be reasonable to extrapolate that members of a collectivist culture make purchasing decisions based on certain features of a package system, such as functionality and potential for multiple-use, although it is true at the same time that citizens of lesser developed countries tend to have a lower level of awareness of environmental issues. It would be reasonable to assume that members of individualistic cultures tend to be more concerned about how a package meets their individual wants and needs and do not concern themselves with a package's impact on the group.

\section{Purpose of the Study:}

Multiple factors (e,g, color, package size, design, price and cultural norms) can influence a purchasing decision. It stands to reason that physical package design can be modified for the purpose of appealing to the differing preferences and values of various cultures. An understanding of the multiple subtle messages that a package design can convey is therefore likely to influence the success of a product in the market place. By investigating differences in consumer perceptions of component containers in a variety of cultures, this study is intended to shed light on an area of great practical importance for a large number of products and companies. A thorough search of the literature uncovered no study similar to 
this one. Although it can be assumed these studies are conducted by a firm and are confidential and not accessible to the general public. For this reason, it is hoped that this study helps to make a contribution to the literature in this area.

\section{METHODOLOGY}

The study presented in this paper involved a Web-based survey of 232 individuals among seven different national groups (Brazil, China, France, Germany, Italy, USA, and Vietnam), soliciting feedback in response to an image of a generic (unprinted) package, querying respondents about their perceptions, feelings, and beliefs in connection with eight different package systems.

\section{Participants:}

This study selected a sampling of 232 respondents from both individualistic and collectivist cultures in both developed and developing countries, distributed geographically in different regions. A master survey was developed in English and subsequently translated into each country's national language. Each survey was translated by individuals whom held a degree from the countries where participants were surveyed. The following table includes the countries surveyed in this study and their societal association based on Hofstede's five dimensional cultural research/study (see Table 1, next page).

The initial target number of participants from each country was 40 , so as to maximize statistical significance. An uncontrolled snowball sampling method was utilized, with researchers sharing the survey web link with friends and family in the seven target countries. Individuals who received the survey link were then asked to pass along the survey link to peers in their country in order to help accumulate participants.
Participants were comprised of individuals who identified themselves as either male or female, were over the age of 18 , and whose participation was voluntary and uncompensated.

\section{Procedure:}

A survey was sent to the participants using 'Survey Monkey,' an on-line database. A survey link was created for each national language in this study. The survey consisted of eight questions concerning eight different package systems. Each of the eight questions related to one of the following aspects of the packaging: creativity, environment, product use, type of product (product appropriateness), hygiene, accessibility (ease of use), and secondary use (see Appendix I for details).

Photographs of the package systems were presented in the survey. All package systems were white and unlabeled, with the exception of a glass jar, which was translucent. The packages chosen for this study were both traditional and new designs. The package systems in question had different features, such as cap-closures and dispensing mechanisms. The package systems also differed in terms of materials and sizes. The eight different package systems included: (1) plastic bottle with twist off cap-closure, (2) Tetra Pak®, (3) plastic tube, (4) stand-up pouch with zip-lock closure, (5) glass jar, (6) folding carton, (7) high-density poly-ethylene (HDPE) bottle with handle, and (8) stand-up pouch with dispenser (see Figure 1 for images).

The survey questions in regard to the perception of the package systems were recorded using a 5-point Likert-scale, ranked as 1= "Strongly Agree" to $5=$ "Strongly Disagree." An open-ended question regarding product type was also asked for each package in the survey. 
Table 1: Countries Surveyed and their Societal Association

\begin{tabular}{lll} 
Country name & $\begin{array}{l}\text { Collectivistic or } \\
\text { Individualistic }\end{array}$ & $\begin{array}{l}\text { Development Status and } \\
\text { Selected Comments }\end{array}$ \\
\hline Brazil & Collectivist (38\% Individualistic) & Developing country \\
China & $\begin{array}{l}\text { Highly collectivist culture }(20 \% \\
\text { Individualistic) }\end{array}$ & $\begin{array}{l}\text { Developing country - growing } \\
\text { consumer population } / \text { market. }\end{array}$ \\
& $\begin{array}{l}\text { Individualistic }(71 \%) \\
\text { France }\end{array}$ & $\begin{array}{l}\text { Developed country } \\
\text { Parents raise their children to be } \\
\end{array}$ \\
\end{tabular}

Individualistic (67\%);

Germany

Highly collectivist compared to the

Developed country US.

Italy Individualistic (76\%)

Developed country.

Personal goals and personal fulfillment are the route to happiness in this group.

Developed country

USA Individualistic (91\%)

The US is one of the most individualistic cultures in the world.

Developing country

Vietnam Collectivist (20\% Individualistic)

Every member takes responsibility of fellow members in the group

*Based on Hofstede, G., Hofstede, G.J. \&Minkov, M. (2010) cultural research study. 


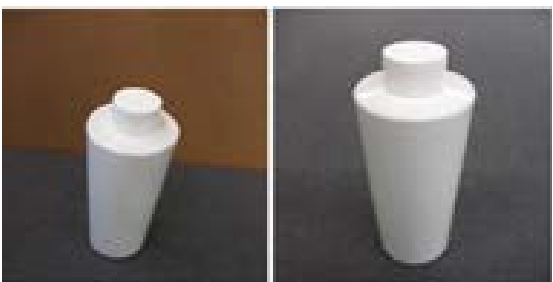

Pkg 1 (Plastic bottle with twist off cap-closure)

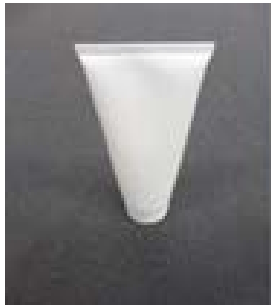

Pkg 3 (Plastic tube)

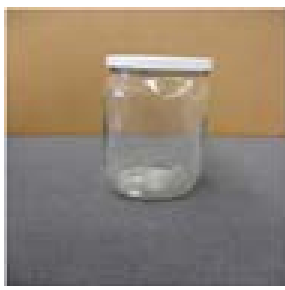

Pkg 5 (Glass jar)
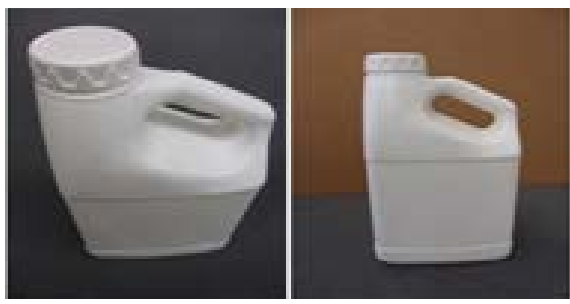

Pkg 7 [High Density Polyethylene (HDPE) bottle]
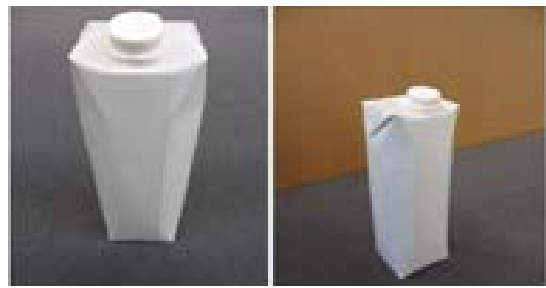

Pkg 2 (Tetra Pak®)
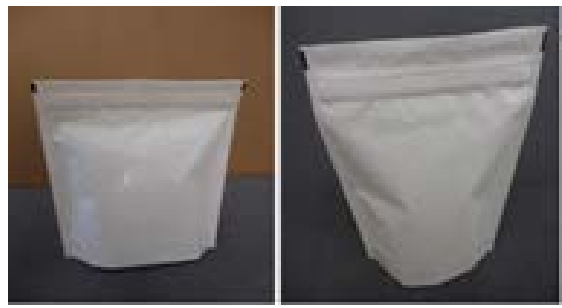

Pkg 4 (Stand-up pouch with zip-lock closure)
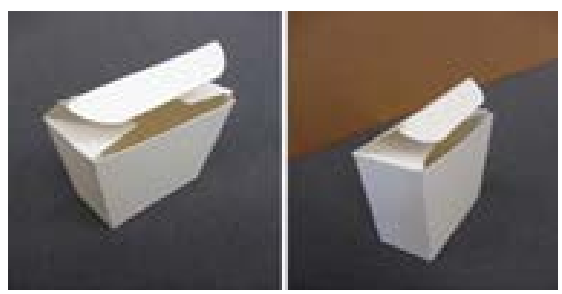

Pkg 6 (Folding carton)

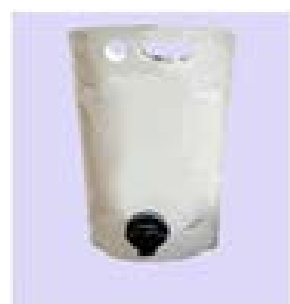

Pkg 8 (Stand-up pouch with dispensing tap)

Figure 1: Eight Package Systems Used in Survey 


\section{Analysis:}

Answer choices for each question were computed to determine whether there were similarities or differences between countries. The most popular answer between the answer choices are presented for each question between countries when possible. Trends and patterns among countries were analyzed, using descriptive statistics. The Minitab ${ }^{\circledR}$ software was used to generate plot graphs to illustrate the results.

\section{RESULTS}

Over a five month period, surveys were collected and trends and patterns were examined to find relationships and differences between perceptions among consumers, in different countries, toward various package systems. A total of 232 participants across all countries took the survey. A table of the number of participants from each country and their demographics are illustrated in Table 2. The key findings with regard to each package system are discussed, and because of a relatively low response rate the most obvious trends are identified and discussed. 
Table 2: Socio-Demographics of the Countries Surveyed $(n=232)$

\begin{tabular}{|c|c|c|c|c|c|c|c|}
\hline & BRAZIL & CHINA & FRANCE & GERMANY & ITALY & USA & VIETNAM \\
\hline $\begin{array}{l}\text { TOTAL } \\
\text { RESPONSES }\end{array}$ & 18 & 34 & 23 & 77 & 18 & 44 & 18 \\
\hline \multicolumn{8}{|l|}{ AGE } \\
\hline $18-25$ & 3 & 13 & 13 & 42 & 2 & 15 & 6 \\
\hline $25-35$ & 5 & 21 & 4 & 33 & 7 & 22 & 9 \\
\hline $35-40$ & 6 & 0 & 0 & 1 & 3 & 1 & 1 \\
\hline $40-50$ & 3 & 0 & 5 & 0 & 5 & 1 & 2 \\
\hline $50-60$ & 0 & 0 & 1 & 0 & 1 & 5 & 0 \\
\hline $60+$ & 1 & 0 & 0 & 1 & 0 & 0 & 0 \\
\hline MALE & 6 & 6 & 7 & 28 & 10 & 23 & 5 \\
\hline FEMALE & 12 & 28 & 16 & 48 & 8 & 21 & 13 \\
\hline GRADE SCHOOL & 0 & 0 & 0 & 0 & 0 & 1 & 0 \\
\hline $\begin{array}{l}\text { SOME } \\
\text { HIGHSCHOOL }\end{array}$ & 1 & 0 & 0 & 0 & 0 & 1 & 0 \\
\hline $\begin{array}{l}\text { HIGHSCHOOL } \\
\text { DIPLOMA }\end{array}$ & 2 & 0 & 0 & 0 & 3 & 2 & 2 \\
\hline SOME COLLEGE & 3 & 3 & 20 & 0 & 9 & 16 & 5 \\
\hline $\begin{array}{l}\text { BACHELORS } \\
\text { DEGREE }\end{array}$ & 11 & 28 & 1 & 0 & 6 & 19 & 11 \\
\hline OTHER & 0 & 0 & 0 & 0 & 0 & 5 & 0 \\
\hline RURAL & 0 & 0 & 0 & 4 & 5 & 0 & 0 \\
\hline SMALL TOWN & 7 & 1 & 3 & 26 & 7 & 4 & 5 \\
\hline SUBURBAN & 0 & 1 & 4 & 7 & 4 & 25 & 0 \\
\hline URBAN & 11 & 31 & 15 & 40 & 2 & 2 & 13 \\
\hline
\end{tabular}




\section{Package 1:}

\section{Plastic Bottle with Twist off Cap-Closure}

The most obvious trend with this package was exhibited in Germany. The German respondents, relative to those from other countries, did not consider this package system to be environmentally friendly (see Figure 2). Respondents from all countries said they would most likely expect to find a health/beauty product in this package system, such as lotion or shampoo. In Vietnam, a few respondents said they expected that such bottles would contain medication (see Figure 3).

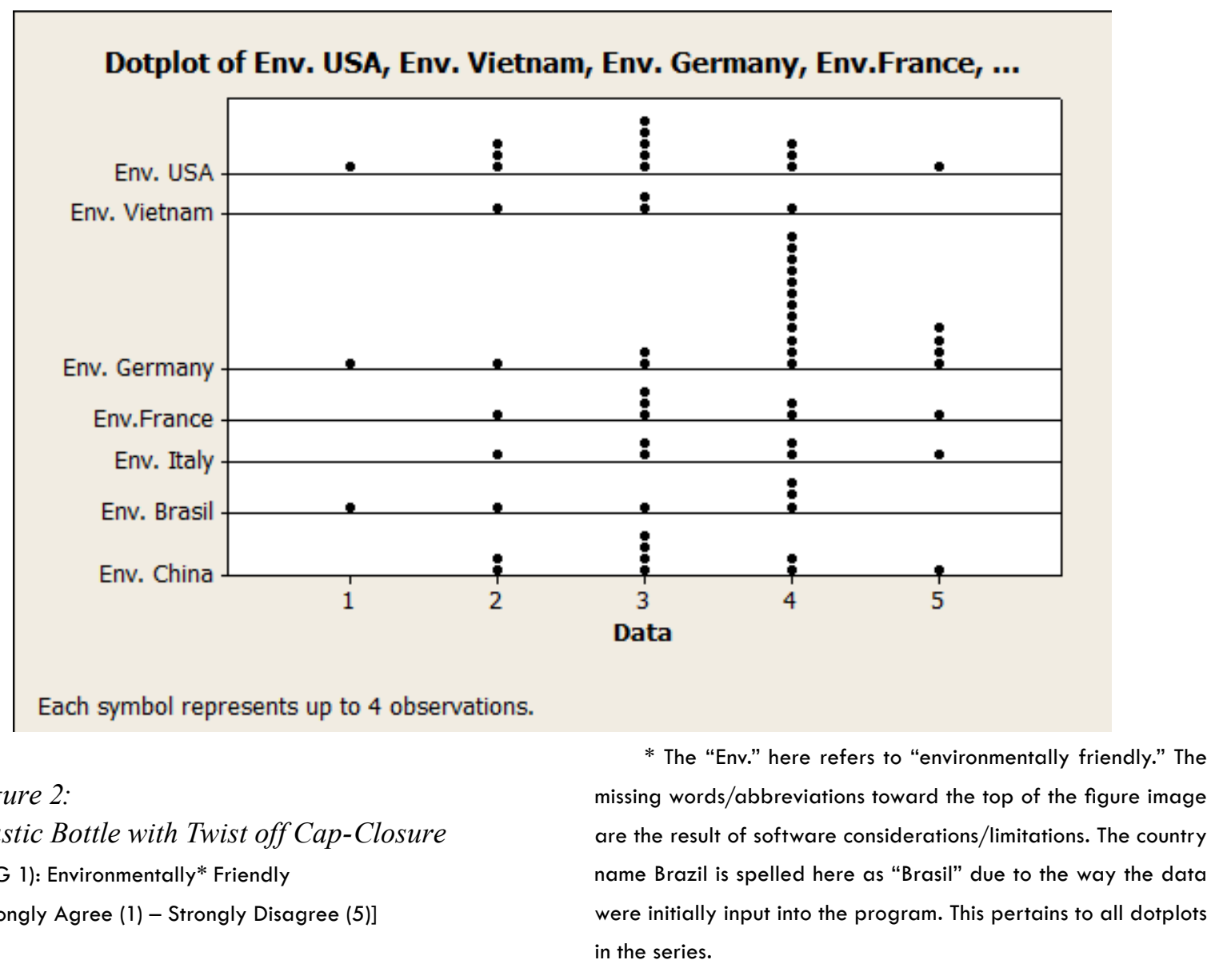




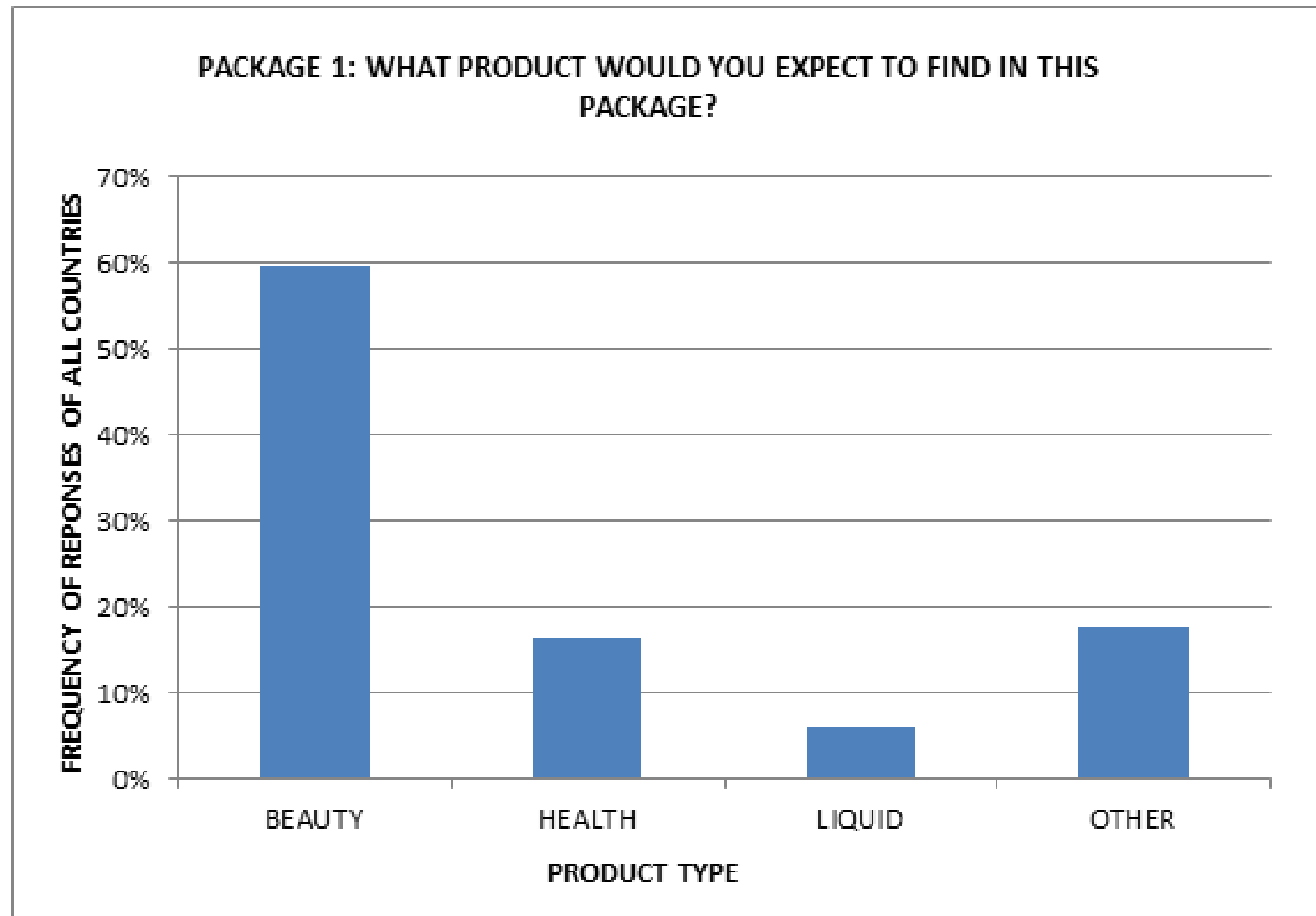

Figure 3:

Plastic Bottle with Twist off Cap-Closure (PKG 1): Product Expectation 


\section{Package 2: Tetra Pak®}

US consumers may be familiar with plastic bottles, tubes and pouches, but the responses for TetraPaks ${ }^{\circledR}$ — compared to respondents from other countries-expressed slight unfamiliarity. Many US respondents $(70.73 \%)$ perceived TetraPaks $\AA$ as a creative package style and also expensive (see Figure 4 and Figure 5), possibly because the system is relatively new to the market introduced in 1984 [12].

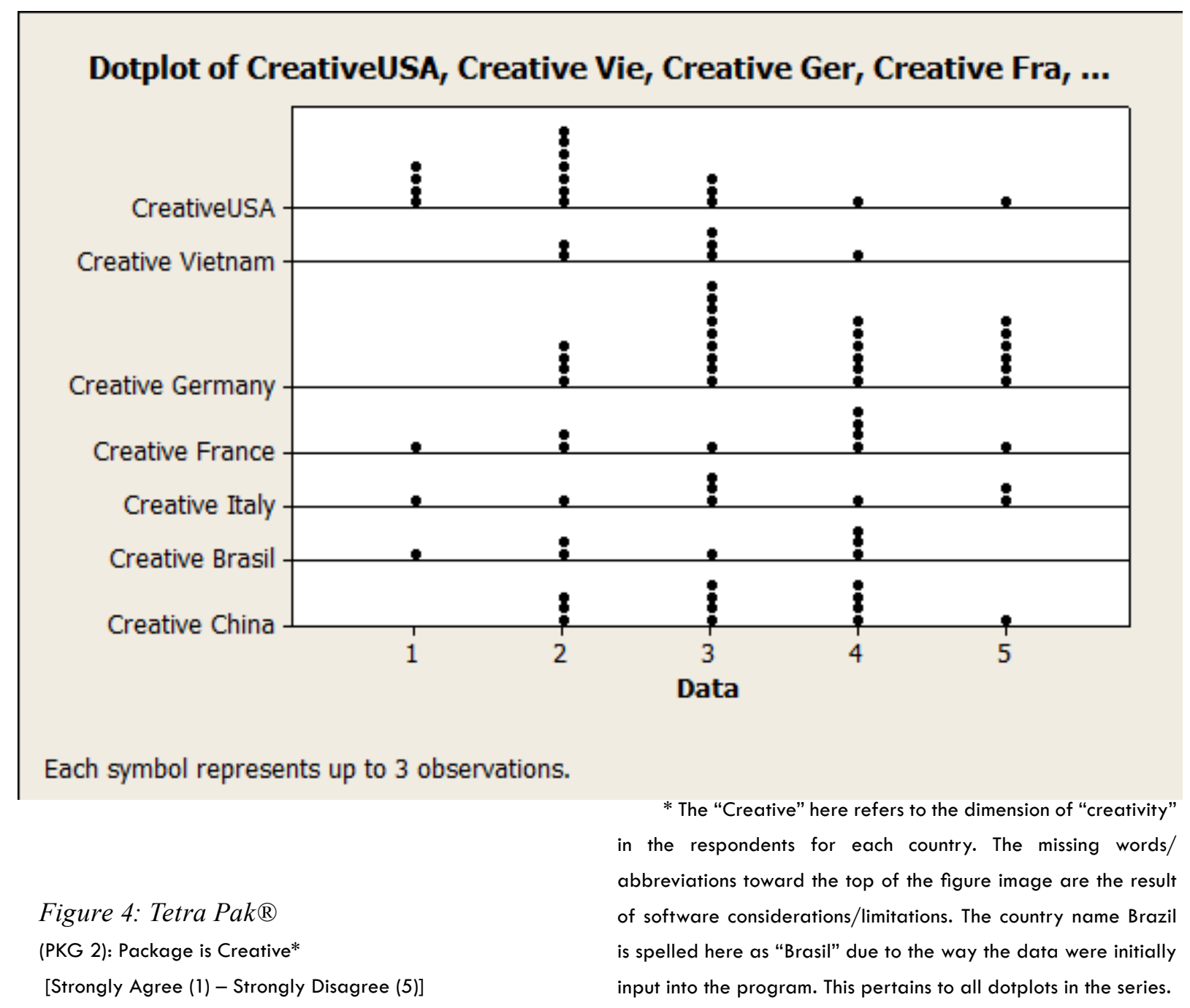




\section{Dotplot of Expense USA, Expense Viet, Expense Germ, Expense Fran, ...}

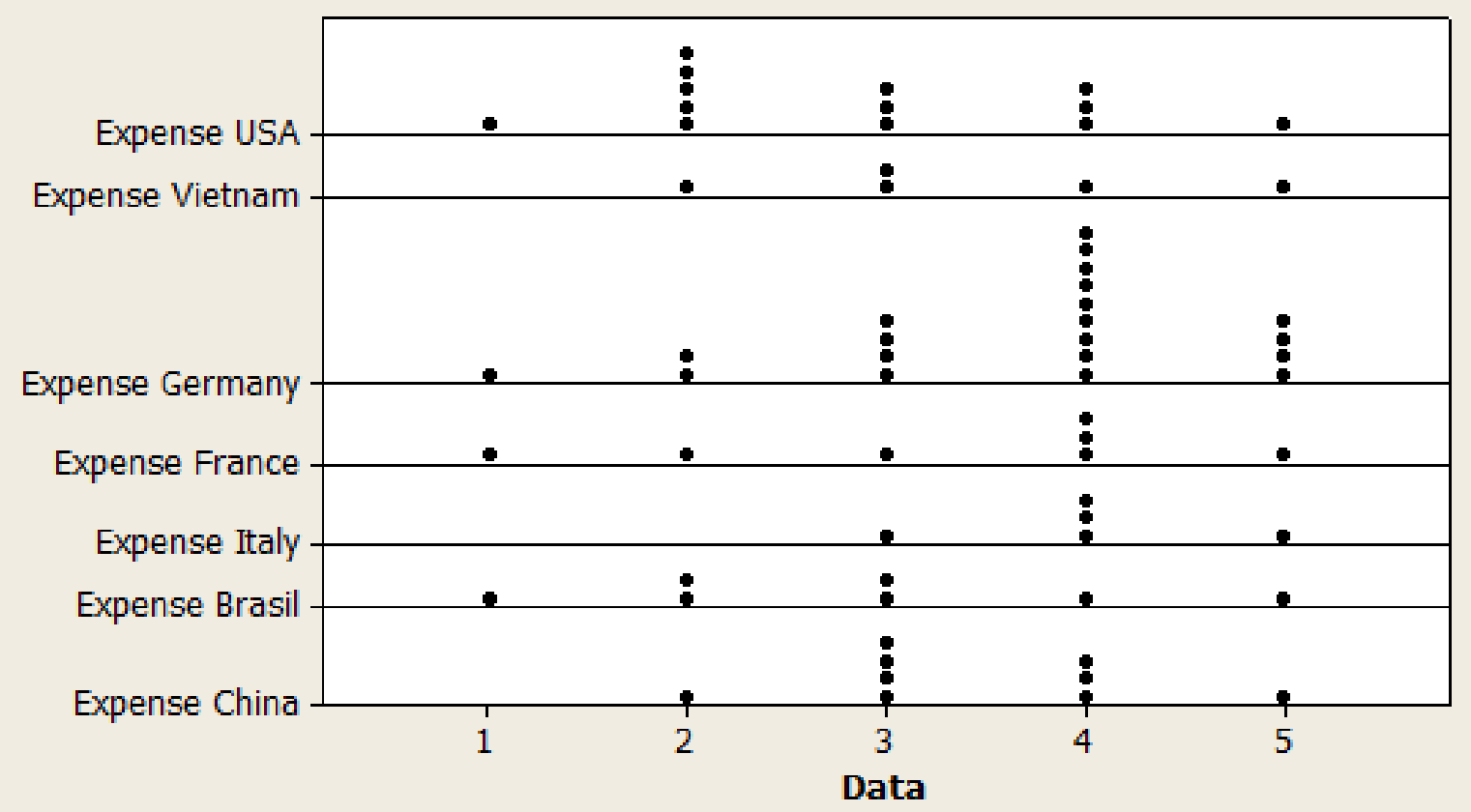

Each symbol represents up to 4 observations.

Figure 5: Tetra Pak®

(PKG 2): Package is Expensive*

[Strongly Agree (1) - Strongly Disagree (5)]

* The word "Expense" here refers to the dimension of the perception of "expense" on the part of respondents for each country. The missing words/abbreviations toward the top of the figure image are the result of software considerations/limitations. The country name Brazil is spelled here as "Brasil" due to the way the data were initially input into the program. 
Although US consumers agree that the familiar cap-closure system makes the package easy to use, responses fell along the lines of a bell-curve with regard to the perception that this package system is expensive. This may relate at least in part to the type of products associated with TetraPaks ${ }^{\circledR}$, such as coconut water, which is viewed as a premium novelty item compared to the other countries surveyed, where it is a more familiar system. According to the study, US consumers understand that the system may hold beverages; however, exotic waters and special (fortified) trendy dairy alternative beverages are also sold in this package system. Additionally, the convenience of this shelf-stable, single servingpackage is promoted to on-the-go Americans, who regard the convenience element as justifying a higher price. Respondents from other countries were more familiar with this package system, because it requires less refrigeration (storage), less power, refrigeration after being opened, and saves energy, which are all beneficial features in countries where consumers typically have limited storage space.

Participants from other countries surveyed agreed that the Tetra $\operatorname{Pak}{ }^{\circledR}$ package was environmentally friendly. This may be due to an awareness of the package system's material and aseptic engineering, which provide the consumer with energy-cost savings and shelf stability. For instance, many non-US participants expressed the expectation that milk (beverages) would be stored in TetraPaks ${ }^{\circledR}$, which are shelf stable until opened in their aseptic packages. Therefore, less energy is required for refrigeration for this product-package system before opening.

\section{Package 3: Tube}

Respondents from all of the countries surveyed expressed familiarity with the package system and agreed that the tube with screw cap would help to protect the product inside. Many countries were split between neutral and disagreeing with whether the plastic tube package with screw cap, was expensive (see Figure 6). For instance, participants' responses may have been either "neutral" or "disagree" with regard to the perception that the product would be expensive, as both high quality and low quality products can be found in these package systems. These mixed perceptions may be a function of the type of product that respondents expected to be in the package. For example, almost all of the respondents said that they expected to find in the plastic tube health care or beauty products, such as toothpaste or moisturizing creams, and this product group contains a variety of high and low end products. 


\section{Dotplot of Expense USA, Expense Viet, Expense Germ, Expense Fran, ...}

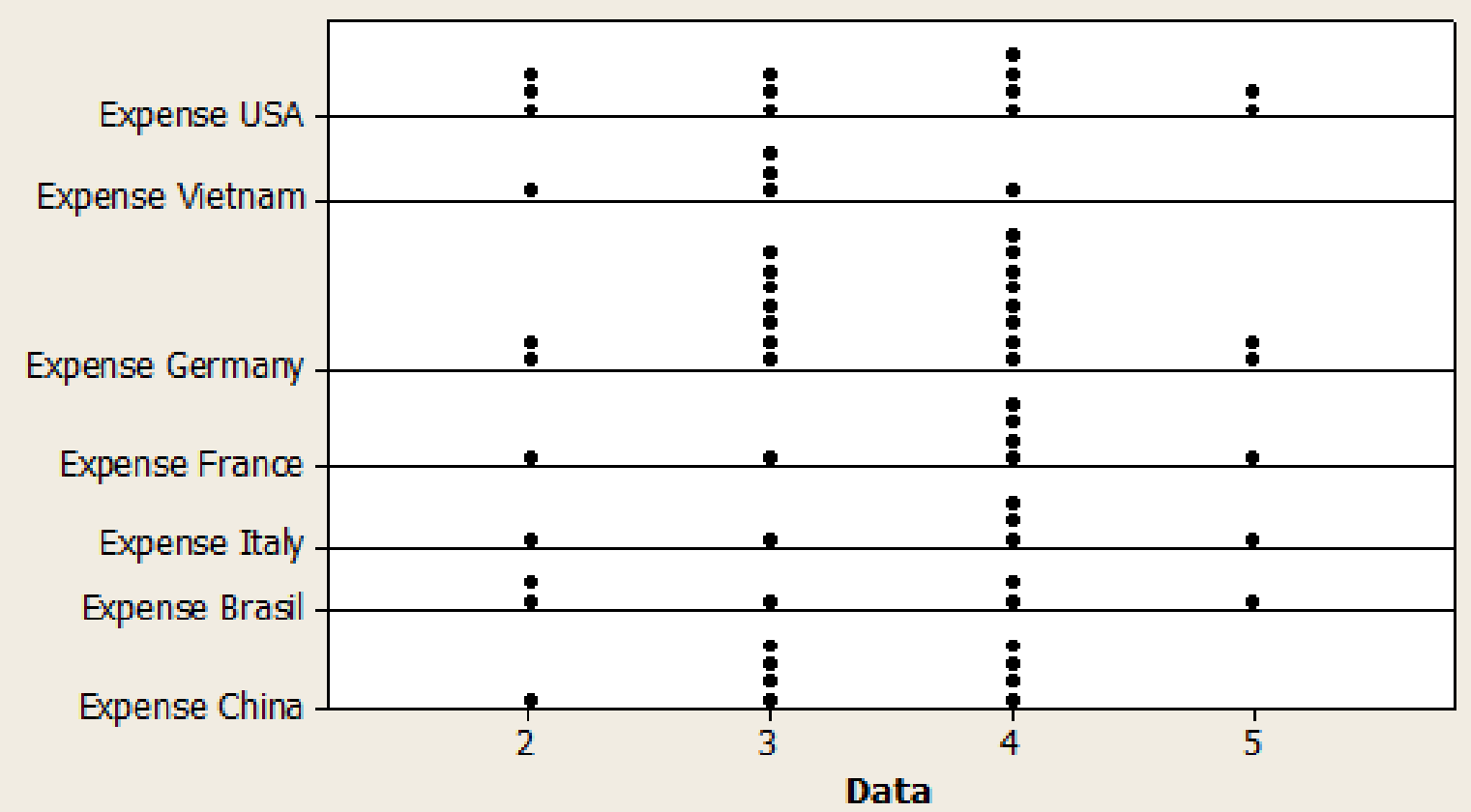

Each symbol represents up to 4 observations.

* The word "Expense" here refers to the dimension of the perception of "expense" on the part of respondents for each country. The missing words/abbreviations toward the top of the

Figure 6: Tube

(PKG 3): Package is Expensive*

[Strongly Agree (1) - Strongly Disagree (5)] figure image are the result of software considerations/limitations.

The country name Brazil is spelled here as "Brasil" due to the way the data were initially input into the program. 


\section{Package 4: Stand-Up Pouch with Zip-Lock Closure}

Many respondents expressed the idea that the stand-up pouch with zip lock closure (package 4) was not environmentally friendly (see Figure 7). This may be because a majority said they would not re-use the package system to store another item, and discard it after use. This may also be due to the demographics of the respondents, such as in Italy, where many respondents declared themselves to be from small towns or rural areas.
This identification may influence people's perceptions of plastic pouches as undesirable, because they create more waste in a demographic where there is a strong desire for package systems that can accommodate multiple uses (see Figure 8).

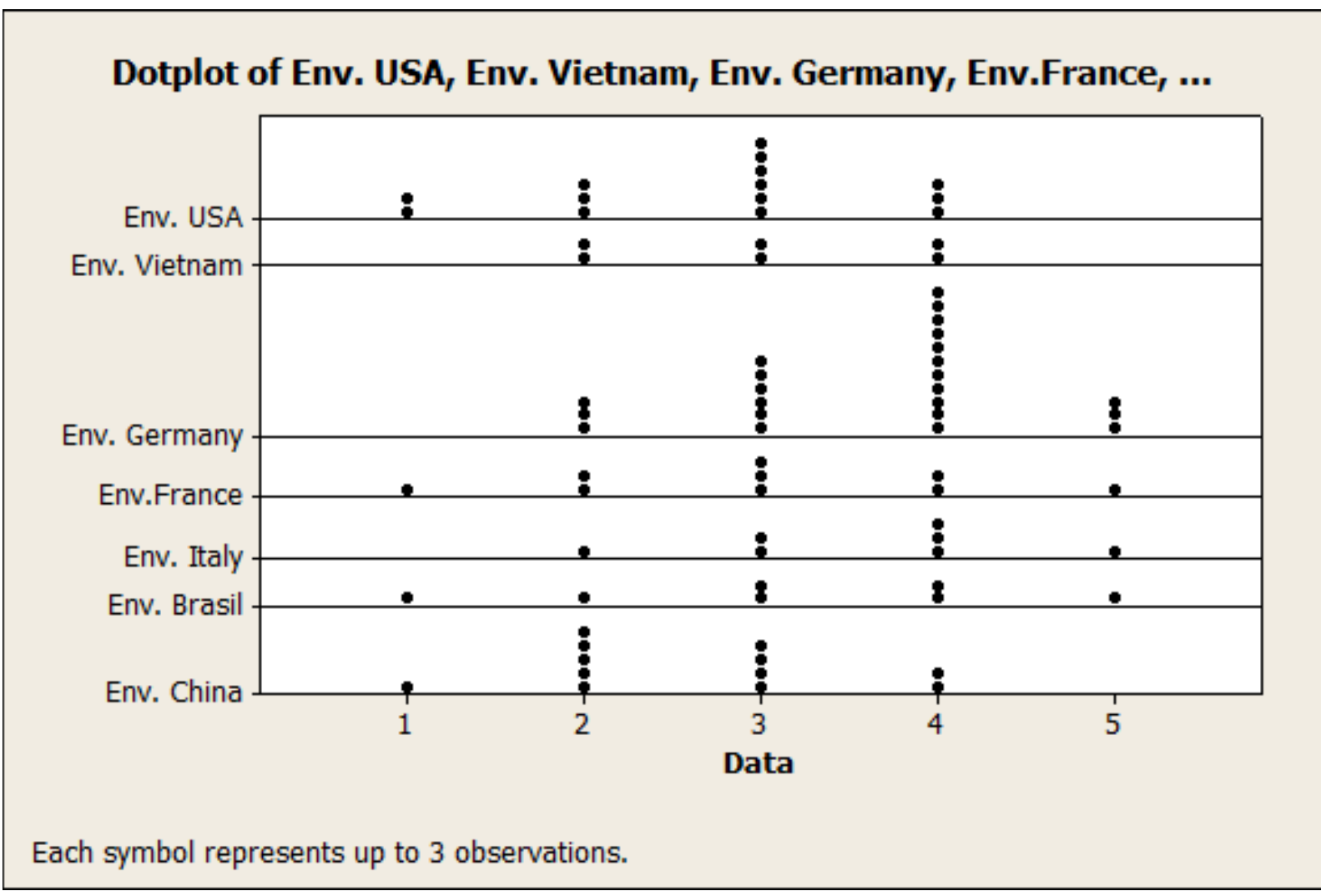

* The "Env." here refers to "environmentally friendly." The missing words/abbreviations toward the top of the figure image

Figure 7: Stand-Up Pouch with Zip-Lock Closure (PKG 4): Package is Environmentally* Friendly [Strongly Agree (1) - Strongly Disagree (5)] are the result of software considerations/limitations. The country name Brazil is spelled here as "Brasil" due to the way the data were initially input into the program. 


\section{Dotplot of Residency}

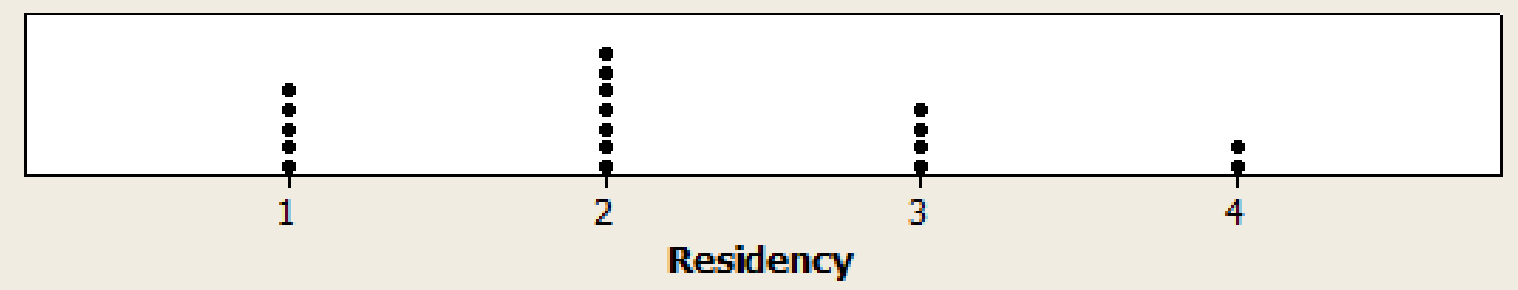

Figure 8:

Demographics of Italian Responses Key:

1. Rural - Farm

2. Small town - In-city

3. Suburban - Outside Town

4. Urban/ City 
Respondents in all countries surveyed agreed in their perception that the stand-up pouch was not expensive. This may be a result of the fact that countries are aware that the type of material used is disposable and relatively inexpensive. Responses from participants in the majority of the countries agreed in their perception that the stand-up pouch with zip lock closure would protect the product inside between uses.
Participants in Germany, however, differed in terms of their agreement with this statement (see Figure 9). The mixed feelings in Germany regarding the package system's protection may be because this group seems more critical and discriminating, with higher expectations relative to package design.

\section{Dotplot of Protect USA, Protect Viet, Protect Germ, Protect Fran, ...}

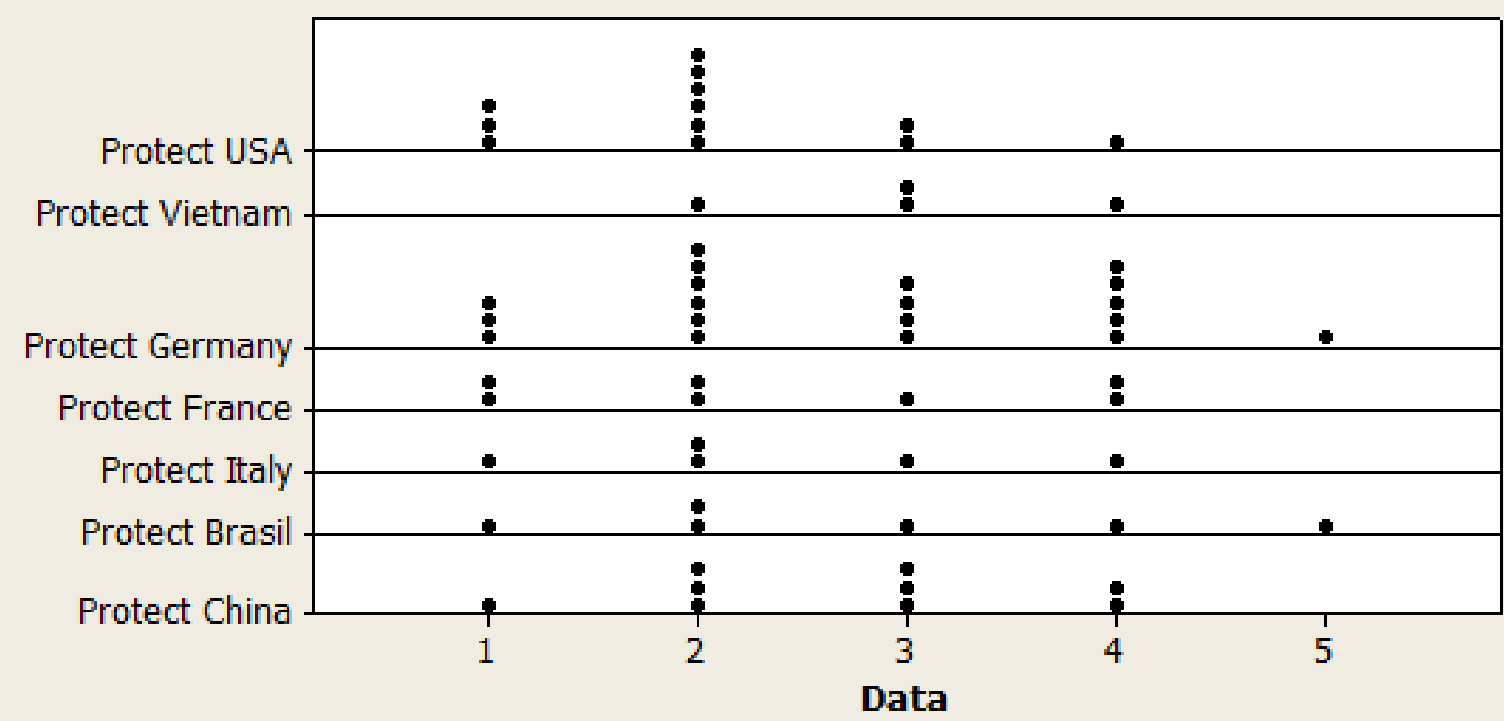

Each symbol represents up to 4 observations.

Figure 9: Stand-Up Pouch with Zip-Lock Dispenser (PKG 4): Package will Protect* the Product [Strongly Agree (1) - Strongly Disagree (5)]
* The word "Protect" here refers to the dimension of the perception of "product protection" on the part of respondents for each country. The missing words/abbreviations toward the top of the figure image are the result of software considerations/ limitations. The country name Brazil is spelled here as "Brasil" due to the way the data were initially input into the program. 


\section{Package 5: Glass Jar}

Glass is a familiar and traditional material that has been used for packaging since 50 B.C., which is why respondents in all of the countries perceived the glass jar with aluminum twist-off lid as being environmentally friendly (see Figure 10), perhaps because of the strong element of reusability [4]. Additionally, survey respondents from the countries surveyed overwhelmingly agreed that this package system is easy to use $(82 \%)$, safe with regard to the stored product $(84 \%)$, and that they would re-use the package system after the original product was finished (100\%).

This may be because the glass material provides transparency, so consumers can actually see their product, which may provide a sense of security, along with product information (being able to see the condition of whatever is in the jars). Also, glass appears to be stronger than the other (plastic) materials included in the survey.

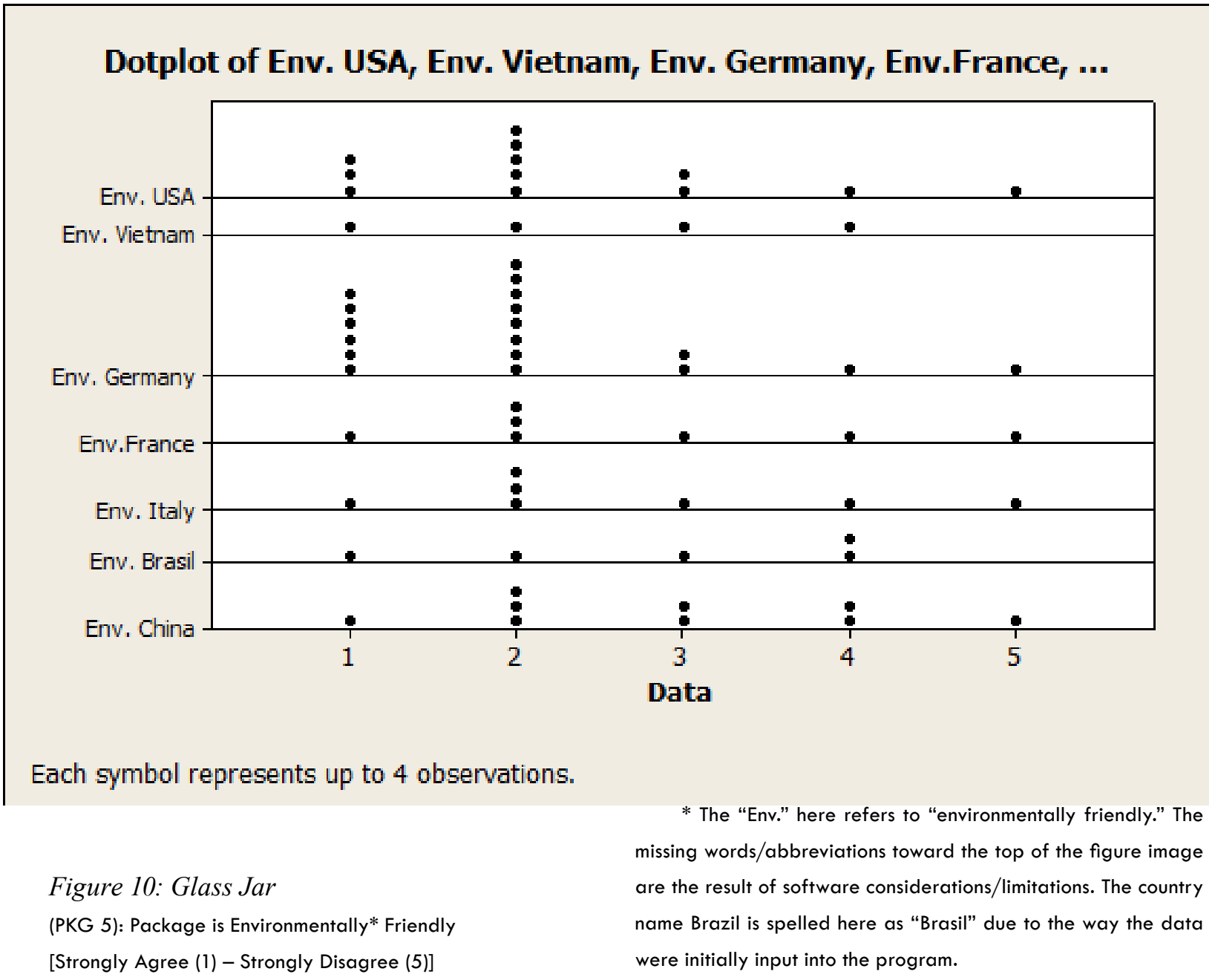




\section{Package 6: Folding Carton}

Unlike the glass jar, the folding carton was perceived by respondents as a one-way package system, not appropriate for secondary use. All respondents in the countries surveyed agreed in their perception that the folding carton was environmentally friendly, possibly because of the familiar material and understanding that the package can be easily recycled (see Figure 11).

\section{Dotplot of Env. USA, Env. Vietnam, Env. Germany, Env.France, ...}

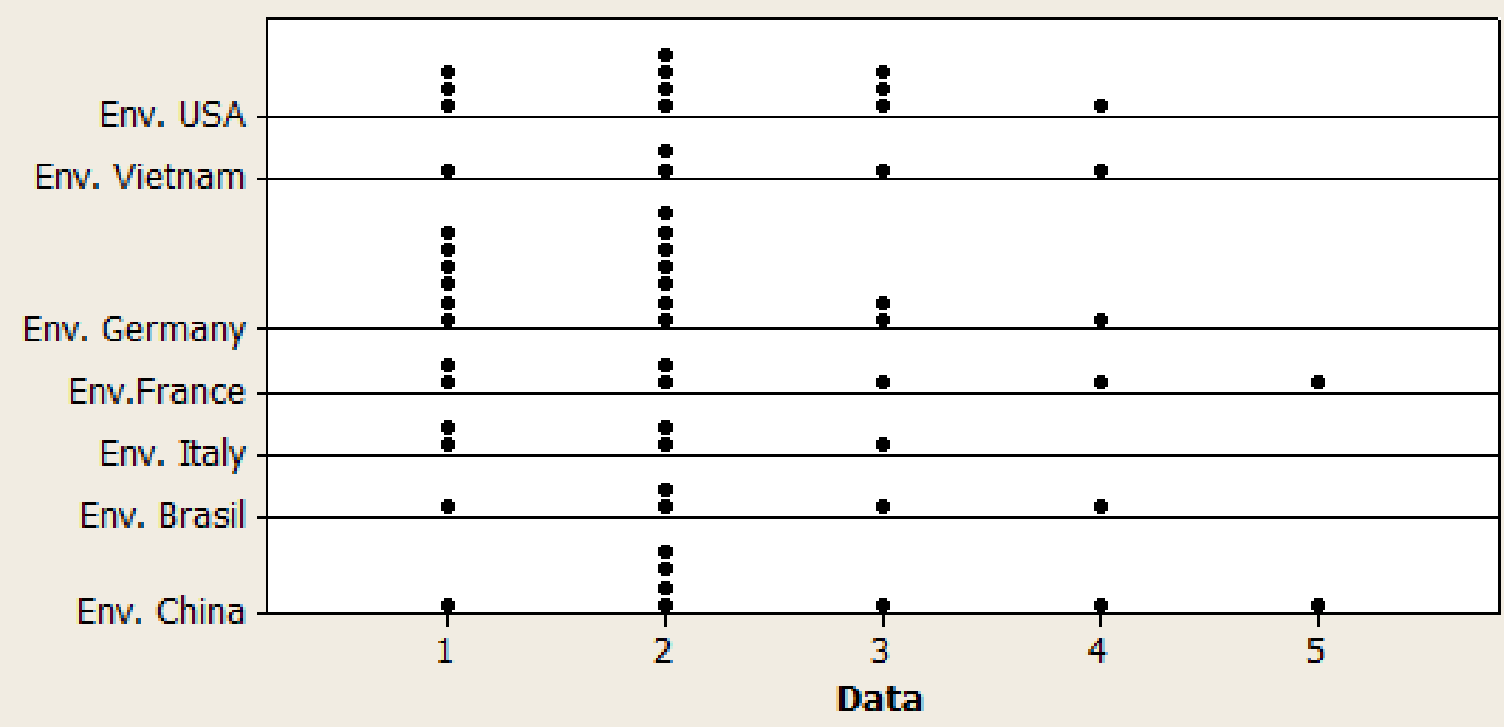

Each symbol represents up to 4 observations.

Figure 11: Folding Carton

(PKG 6): Package is Environmentally* Friendly

[Strongly Agree (1) - Strongly Disagree (5)]
* The "Env." here refers to "environmentally friendly." The missing words/abbreviations toward the top of the figure image are the result of software considerations/limitations. The country name Brazil is spelled here as "Brasil" due to the way the dato were initially input into the program. 


\section{Package 7:}

\section{High Density Polyethylene (HDPE) Bottle with Handle}

The majority of participants from the various countries did not consider the HDPE bottle to be environmentally friendly (see Figure 12). Respondents from all countries agreed that the system was easy to use and would provide the product with protection, but the majority of the respondents across the spectrum also expressed the idea that they would not use the package system after they were done with it (no secondary use). In this survey the Germans collectively believed that this package system was not environmentally friendly.
The idea of the package system as unsuitable for secondary use may have increased the idea of the package as a high material consumption item for the German respondents (see Figure 13) [30]. Participants from Brazil in particular perceived the products in this package system as expensive. This may be because they are used to purchasing smaller packages such as sachets for immediate use, rather than items normally found in this type of container. Brazilians may have also perceived this package as expensive because of the types of product with which it is associated, such as cleaning products or motor oil.

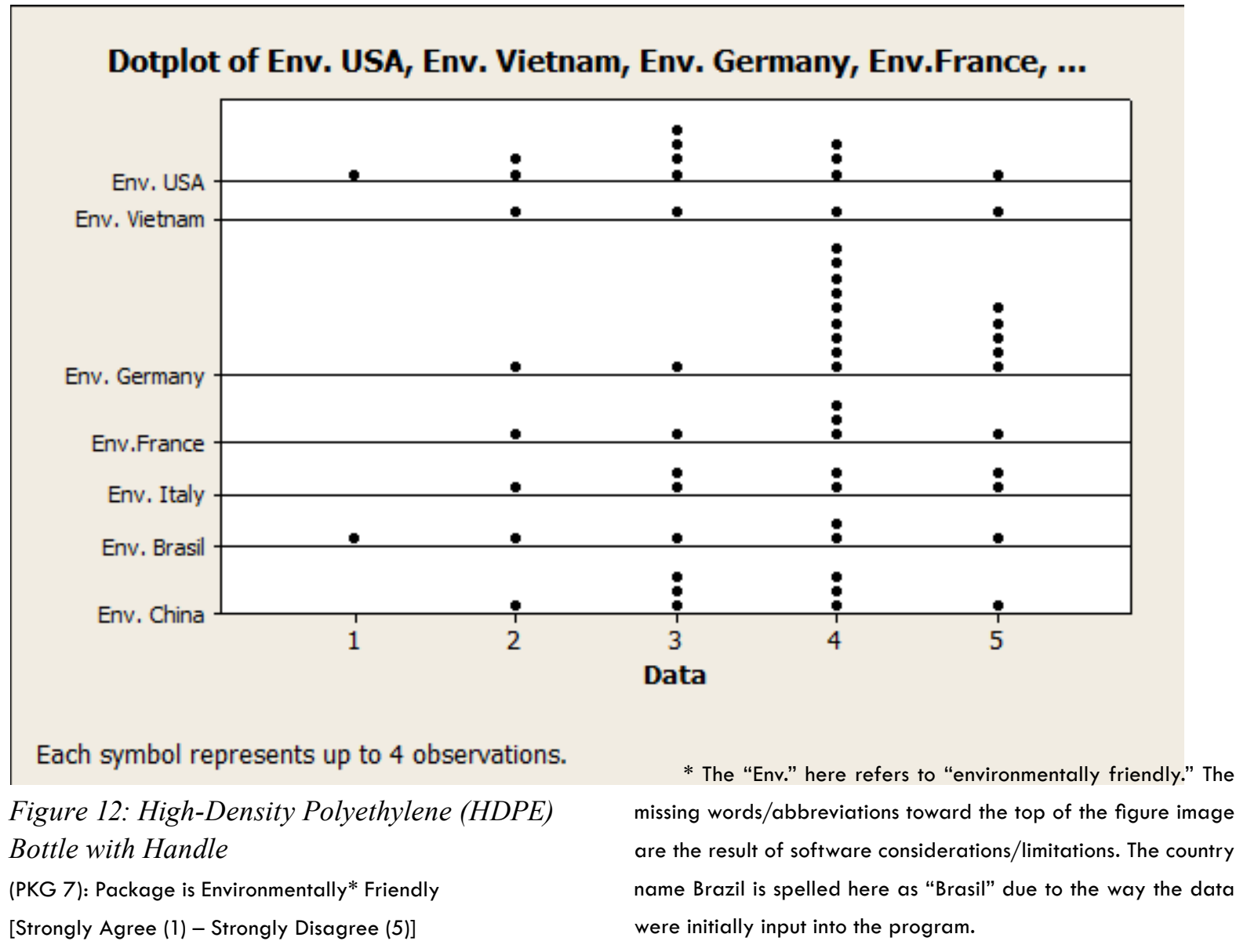




\section{Dotplot of SecondaryUse, SecondaryUse, Secondary Us, Secondary Us, ...}

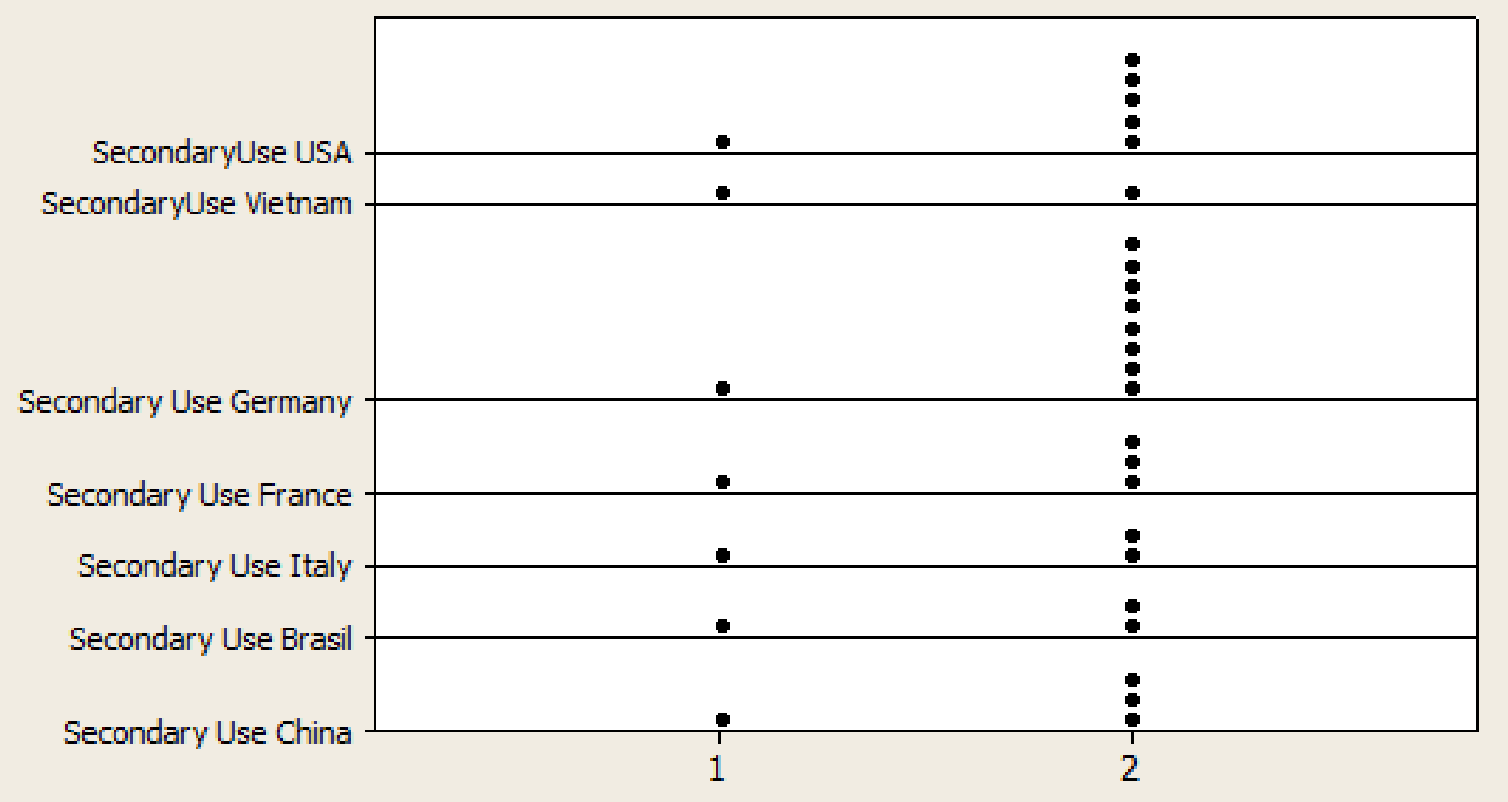

Data

Each symbol represents up to 7 observations.

Figure 13: High Density Polyethylene (HDPE)

Bottle with Handle

(PKG 7): Package used for Secondary Use*

[Yes (1) - No (2)]
* The "SecondaryUse" here refers to the dimension of the perception of "Secondary Usage" (re-using), of the package system in question, on the part of respondents for each country. The missing words/abbreviations toward the top of the figure image are the result of software considerations/limitations. The country name Brazil is spelled here as "Brasil" due to the way the data were initially input into the program. 


\section{Package 8: Stand-Up Pouch with Dispenser}

Many Germans disagreed that the package styles in the survey were creative, except for Package 8 , the stand-up pouch with dispenser, which may be because the package system is not as prevalent in the market. German respondents were divided as to whether this package system was available to them in their country (see Figure 14).

\section{Dotplot of Available US, Available Vi, Available Ge, Available Fr, ...}

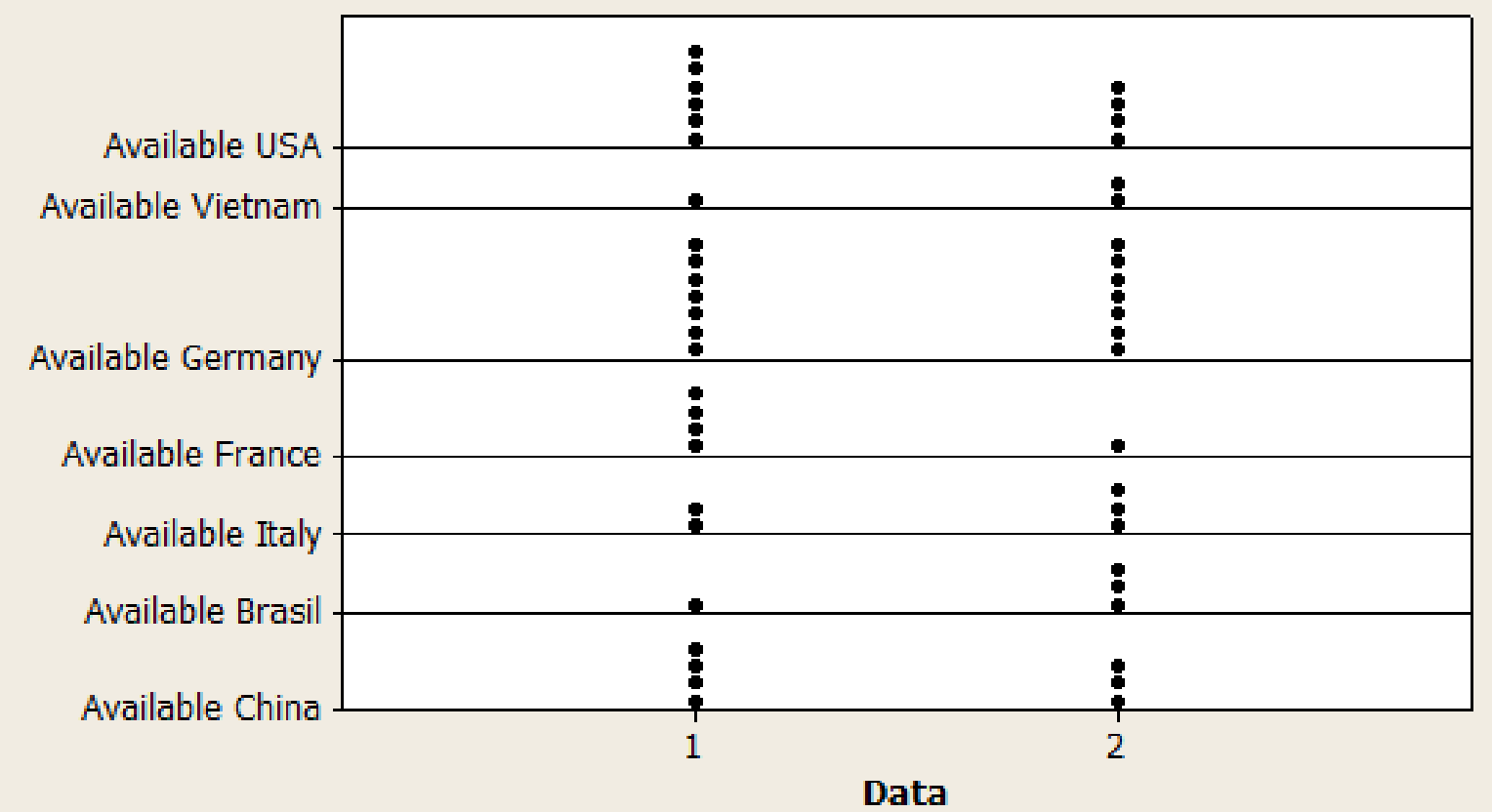

Each symbol represents up to 4 observations.

Figure 14.Stand-Up Pouch with Dispenser (PKG 8): Package is Available* [Yes (1) - No (2)]
* The "Available" here refers to "availability" in the individual country. The missing words/abbreviations toward the top of the figure image are the result of software considerations/ limitations. The country name Brazil is spelled here as "Brasil" due to the way the data were initially input into the program. 
Although French respondents seemed more familiar with package 8 , they were neutral as to whether they believed that package 8 was environmentally friendly. The majority of the respondents $(53 \%)$ said that they would expect to find wine in this package. The takeaway from this information is that in France this package is being used primarily for wine.

This package style and material may be regarded by the French as an inferior substitute for the traditional glass wine bottle. Since the package system is disposable and has a short life cycle, the perceived value of the beverage inside may be correspondingly reduced, together with the perception that the package system creates more waste. A majority of the French respondents expressed the idea that the stand-up pouch with dispensing fitment was expensive, possibly because the package does not lend itself to being reused. The cost of the beverage in the alternative package system may not actually be different from its cost in the traditional package system, the glass bottle, even though it is stored in a package that is perceived as being of lower quality. This is possibly due to the package system being viewed as a one-time use package (oneway package system), designed primarily for convenience, in contrast with the traditional system of a glass bottle, which can be refilled or reused. According to Alter [31], the French have created a re-fill wine system, where customers can bring in empty glass bottles and fill them with local wine at the grocery store. This system lowers the carbon footprint by reducing material waste, usage, and distribution greenhouse gasses.

\section{General Trends:}

Respondents in all countries surveyed agreed that the package systems with cap-closures were easy to use. This may be because of the near-universal familiarity with this type of closure system. Based on the responses in this study, the cap-closure systems were perceived as a hygienic feature that would protect the product through multiple uses, and that the cap-closure may enhance shelf stability for the product.

Respondents in all countries surveyed expressed the idea that glass material is environmentally friendly. These impressions seem understandable because of the position of glass as a traditional package system, in use for many years, and associated with a high level of trust. More education on the energy involved in processing and transporting glass material may change view points for consumers, however. Although glass is an inert material that can be reused repeatedly, its heavier material increases carbon footprint in transportation, in comparison with flexible, plastic package alternatives.

Compared with all of the countries surveyed, German respondents seemed to be more critical than those of other countries with regard to environmentally friendly package systems, reflecting the high level of awareness of environmental issues in that country.

\section{LIMITATIONS}

The initial goal for this research was to obtain 40 participants from each of the seven countries. Recruiting participants proved difficult, probably because there was no material incentive or sense of urgency from their perspective to take the survey. Vietnam had an unforeseen limiting factor that could have influenced the low response rate. Vietnam has The Decree 72 law, which restricts people from quoting or sharing news stories on social networks [32]. This law may have caused hesitation and concern among those that received the survey link, even though participation in this survey would not 
actually have been at odds with this decree. Another common limitation in this type of investigation may have been the length of the survey. It is possible that participants lost interest in the survey because of its length. It is also possible that the length of the survey increased the likelihood that some participants would become bored and not answer thoroughly. In developing countries, limited access to computers or the cost of public computer use may have resulted in a lower response rate in those groups.

\section{DISCUSSION}

Due to the relatively lower response rates from the other countries surveyed, Germany and the US are the two best countries to use for purposes of understanding the differences between a collectivist and individualistic societal orientation.

\section{Collectivist:}

Germany is a socio-economically developed country with a growing middle class. Although a majority of the country (67\%) is considered individualistic [14], Germany is well known for its environmental consciousness and strong nationalistic beliefs, which may help to explain the more critical responses of respondents in certain areas, compared with respondents in other countries. A developed country with a large middle class, Germans are known for their strong environmental awareness, as reflected in German respondents demonstrating more collectivistic values in answering the package sustainability section of the survey. As a developed country with an expanding economy, Germans are becoming more demanding about preferences with regard to package styles and an environmentally sound system seems to be one preference [33].

\section{Individualistic:}

The US is a developed and highly individualistic society according to Hofstede et al. [14]. As a developed country, US consumers can purchase a week's worth of groceries and have enough refrigeration and storage space to keep goods from perishing quickly. More limited storage space obliges consumers in Asian and European countries to shop more frequently. This difference may help to explain why US respondents viewed the Tetra Pak ${ }^{\circledR}$ as a creative new package design, while respondents from other countries surveyed viewed the Tetra Pak ${ }^{\circledR}$ as an eco-friendly and shelf-stable package option for perishable beverages such as milk. US respondents viewed the package system as being modern and trendy, anot her way of expressing personality in a highly individualistic society. In the U.S. the Tetra Pak ${ }^{\circledR}$ is being used for innovative products, and milk is not accepted in this package in the U.S. This may be due to Americans storing milk under refrigeration. Respondents from other countries viewed the Tetra $\operatorname{Pak}{ }^{\circledR}$ for its functional features, such as increasing shelf-stability, lower environmental impact, and hygienic protection of the product.

\section{Product Perception and Location:}

Germany and France are two geographically close countries, both with developed economies. It is beyond the scope of this study but was nonetheless interesting to find that respondents from these two countries expressed different answers. While Germans respondents expressed mixed feelings as to whether the stand-up pouch with dispenser (package 8) was available in their market, the French agreed that package 8 was available to them. It seems reasonable to assume that the reason that Germans were divided on the question as to the availability of this package system in their country is that this 
package system is most appropriate for wine, of which the Germans are not great consumers. For the same reason, it seems reasonable to assume that the French, in contrast overwhelmingly agreed on the availability of this package system in their country, as the French are well known to be heavy consumers of wine and have an elevated understanding of the product. The French respondents did not regard the light-weight, recyclable package 8 as a cheaper alternative to the traditional glass bottle, probably because of the common practice in France of employing glass wine bottles as a refillable and economical container choice for wine.

\section{Final Thoughts:}

This research supports the idea that product perception may influence consumer views with regard to both price and quality. Cultural factors, along with socio-economic variables, may influence purchasing choices. Consumers in countries that are developing and collectivist in orientation may be more inclined to purchase product-package systems that are geared toward functionality, providing for basic needs. Consumers in countries that are developed and individualistic in orientation may be more inclined to purchase products whose packaging is more aspirational in nature, also offering character and convenience. Various aspects of package design, including convenience, environmental sustainability, or shelf-stability can impact how members of a particular country relate to the package, thereby influencing their purchasing decisions. It is hoped that this research may be useful for companies exporting or seeking to export their products into other markets. In five years, it may be interesting to investigate in future work whether economic growth in the countries studied may affect their cultural association and consumer perceptions. 


\section{REFERENCES}

[1] Silayoi, P., \&Speece, M. (2004). Packaging and purchase decisions: An exploratory study on the impact of involvement level and time pressure, British Food Journal, 106, 607 - 628. doi: 10.1108/00070700410553602

[2] Venter, K., Merwe, D., Beer, H., Kempen, E., \& Bosman, M. (2011). Consumers' perceptions of food packaging: an exploratory investigation in Potchefstroom, South Africa. International Journal of Consumer Studies, 35, 273-281. doi: 10.1111/j.1470-6431.2010.00936.x

[3] Definition of Packaging. (2010, May 10). Retrieved from http://www.doeni.gov.uk/ niea/wastehome/regulation/regulations packaging/definition_of_packaging.htm

[4] Soroka, W. (1995). Fundamentals of Packaging Technology. Herndon, VA: Richard Warrington

[5] The Purposes of Packaging. In Boundless Marketing (Ch. 10).(n.d.) Retrieved from: https://www.boundless.com/marketing/ textbooks/boundless-marketing-textbook/ branding-packaging-10/packaging-75/thepurposes-of-packaging-379-4135/

[6] U.S. Department of Health and Human Services, Food and Drug Administration, Center for Drug Evaluation and Research (CDER), and Center for Biologics Evaluation and Research (CBER), (1999, May). Guidance for Industry Container Closure Systems for Packaging Human Drug and Biologics. Retrieved from http:// www.fda.gov/downloads/Drugs/Guidances/ ucm070551.pdf
[7] Scheuneman, H. (n.d.) Package Engineering Design and Testing. Retrieved from http:// www.westpak.com/images/pdf/08 package_engineering_design_testing.pdf

[8] What Is a Unit Load? (2014). Retrieved from http://www.wisegeek.com/what-is-a-unitload.htm\#comments

[9] Yam, K. L. (2009) The Wiley Enyclopedia of Packaging Technology, 3rd edition.

Retrieved from http://pkt.jinakarn.com/ept. pdf

[10] Weatherford, R. (n.d.) The Role of Conspicuous Consumption in Branding and Positioning.Retrieved from http://www. neumann.edu/academics/divisions/business/ journal/review2013/weatherford.pdf.

[11] Barber, N. \& Almanza, B. (2006). Influence of Wine Packaging on Consumers' Decision to Purchase, Journal of Foodservice Business Research, 9, 83-98. doi: 10.1300/ J369v09n04_06

[12] Tetra Pak ${ }^{\circledR}$ Group (2013). Tetra Pak ${ }^{\circledR}$ Development in Brief.Retreived from http:// www.tetrapak.com/documentbank/9704en. pdf

[13] Protects What's Good. (2014). Retrieved from http://www.tetrapak.com/about-tetrapak/the-company/protects-whats-good.

[14] Hofstede, G., Hofstede, G.J., and Minkov, M. (2010).Cultures and Organizations: Software of the Mind. Revised and Expanded 3rd Edition. USA: McGraw-Hill

[15] [15] Yousaf, S. \& Hauibin, L. (2013). Profiling Consumer Behavior in the Context of Involvement Level and Demographic Factors: Evidence of Within-Country Differences From a Developing Economy, Journal of Global Marketing, 26 (1), 1-17, doi: 10.1080/08911762.2013.779404 
[16] Kaynak, E. (1985). Cross-Cultural Food Buying Behavior.Retrieved from http:// www.acrwebsite.org/search/viewconference-proceedings.aspx?Id=12120

[17] Tariq, M., Nawaz, M. R., Nawaz, M.M., \& Butt, H. (2013). Customer Perceptions about Branding and Purchasing Intention: A study of FMCG in an Emerging Market. Journal of Basic and Applied Scientific Research, 3, 340-347.

[18] Grimsley, S. (2014).What isBrand Loyalty in Marketing? Definition, Examples and Quiz. Retrieved from http://education-portal.com/ academy/lesson/what-is-brand-loyaltyin-marketing-definition-examples-quiz. html\#lesson

[19] Every breakthrough product needs an Audience. (2013, January).

Retrieved fromhttp://www.nielsen. com/content/dam/corporate/au/en/ NielsenGlobalNewProductsReportFINAL. pdf

[20] Crazchyi (2012).Does People in Developing Countries spend less (or more)? Development Economics, Laos. Retrieved from: /07/31/does-http://crazchyi.wordpress. com/2012people-in-developing-countriesspend-less-or-more/

[21] Guo, X. (2013). Living in a Global World: Influence of Consumer Global Orientation on Attitudes Toward Global Brands from Developed Versus Emerging Countries, Journal of International Marketing, 21(1), 1-22.http://dx.doi.org/10.1509/jim.12.0065
[22] Feliciano, J. (2013). Small Packaging Increases Access, Raises Value in Emerging Asian Markets.Euromonitor International. Retrieved from: http://blog.euromonitor. com/2013/10/smaller-packaging-increasesaccess-raises-value-in-emerging-asianmarkets.html

[23] Bonnardel, V., Beniwal, S., Dubey, N., Pande, M., Bimler, D. (2012). Color preferences: a British/Indian comparative study. Academina.edu. (AIC).Retrieved from: http://www.academia.edu/4205575/ Color_preference_a_British_Indian_ comparative_study

[24] Aslam, M. (2006). Are you Selling the Right Colour? A Cross-cultural Review of Colour as a Marketing Cue. Journal of Marketing Communications, 12, 15-30. doi: 10.1080/13527260500247827

[25] Madden, T.J., Hewett, K., \& Roth, M.S. (2000). Managing Images in Different Cultures: A Cross-National Study of Color Meanings and Preferences.Journal of International Marketing, 8 (4), 90-107.

[26] Corduas, M., Cinquanta, L., Ievoli, C. (2013). The importance of Wine for Purchase decisions: A Study of Italian Consumer's Perception. Food Quality and Preference, 28, 407-418. doi: 10.1016/j. foodqual.2012.11.007

[27] Venter, K., Merwe, D., Beer, H., Kempen, E., \& Bosman, M. (2011). Consumers' perceptions of food packaging: an exploratory investigation in Potchefstroom, South Africa. International Journal of Consumer Studies, 35, 273-281. doi: 10.1111/j.1470-6431.2010.00936.x 
[28] Oh, S. (2013). Do Collectivists Conform more than Individualists? Cross-

Cultural Differences in Compliance and Internalization.Social Behavior and Personality, 41, 981-994. http://dx.doi. org/10.2224/sbp.2013.41.6.981

[29] Mooij, M. \& Hofstede, G. (2011). CrossCultural Consumer Behavior: A Review of Research Findings. Journal of International Consumer Marketing, 23, 181-192. doi: 10.1080/08961530.2011.578057

[30] Meyer, B., Distelkamp, M., \&Wolter, M. (2007). Material Efficiency and EconomicEnvironmental Sustainability. Results of Simulations for Germany with the Model PANTA RHEI [Abstract]. Ecological Economics, 63, 192-200. DOI: 10.1016/j. ecolecon.2006.10.017

[31] Alter, L. (2010, September 5). New Wine in Old Bottles: The Greenest Way to Drink. Retrieved from: http://www.treehugger.com/ green-food/new-wine-in-old-bottles-thegreenest-way-to-drink.html

[32] Palatino, M. (2013, August 8). Decree 72: Vietnam's Confusing Internet Law. The Diplomat. Retrieved from: http:// thediplomat.com/2013/08/decree-72vietnams-confusing-internet-law/

[33] McCabe, K. \&Rehder, E.L. (2013). Good Market Opportunities for U.S. Exporters of Consumer Oriented Agricultural Products. GAIN Report. Retrieved from:http:// gain.fas.usda.gov/Recent\%20GAIN\%20 Publications/Exporter\%20Guide_Berlin_ Germany_4-25-2013.pdf 


\section{APPENDIX I}

Survey Instrument | Survey Questions

\section{DEMOGRAPHIC QUESTIONS}

What is your age range?
a) $18-25$
b) 25-35
c) $35-40$
d) $40-50$
e) $50-60$
f) $60+$

What is your gender?
a) Male
b) Female

What is the highest level of education you have completed?
a. Grade school
b. Did not finish High School
c. High School diploma
d. Some college
e. Bachelor's degree
f. Other:

Where do you currently reside?
a. Rural-Farm
b. Small town - In-city
c. Suburban - Outside Town
d. Urban/ City

\section{SURVEY QUESTIONS}

Below are questions regarding thoughts/feelings towards the pictured package. Please indicate to which extent you agree or disagree with the following questions.

1) What product would you expect to find in this package?

2) Is this package environmentally friendly? 1-Strongly Agree

2-Agree

3-Neutral

4-Disagree

5-Strongly Disagree

3) Does this container look expensive? 1-Strongly Agree

2-Agree

3-Neutral

4-Disagree

5-Strongly Disagree

4) Once you have completely used the product in the package, would you use this package for another use?
a. Yes
b. No
c. If yes, then what: 
5) Does this package look easy to use, easy to open/close? Can you easily dispense the product?

1-Strongly Agree

2-Agree

3-Neutral

4-Disagree

5-Strongly Disagree

6) Does this package have a creative style?

1-Strongly Agree

2-Agree

3-Neutral

4-Disagree

5-Strongly Disagree

7) If you did not finish the product in this package, do you think this package will protect the product until the next use?

1-Strongly Agree

2-Agree

3-Neutral

4-Disagree

5-Strongly Disagree

8) Is this package style currently available to you?

a. Yes

b. No 